\title{
The relative value of cultures in liquid and solid media in the diagnoses of bacteria.
}

\author{
THEOBALD SMITH.
}

The marked progress recently made in the study of microorganisms as the cause of certain diseases is without doubt due to the more thorough application of various solid culture media by Koch and his pupils. Today the microscope does not hold the chief place in the study of these minute organisms. It is their mode of growth upon gelatine, blood serum, agar-agar, potato, in meat infusions, milk, etc., or the absence of growth on one or more of these substances and in these fluids which aids in confirming the mieroscopic examination. For this frequently yields results so indefinite that without the media mentioned it is impossible to come to any satisfactory conclusions as to the kind of bacteria under consideration. Besides these various tests, inoculation experiments are of essential importance in the iuvestigation of pathogenie forms.

In connection with the cultivation of bacteria for diagnostic purposes, it is again desirable to call attention to liquid media and their uses. The statements of Koch and others several years ago concerning the unreliability of liquids have almost driven them from the field in Germany and in our own country.

Pasteur, the founder of this new and brilliant branch of pathology, made cultures in meat broths or decoctions exclusively. That grave errors may arise in this way through contaminations which can not be easily detected is self-evident. When gelatine and other solid media were introduced by Koch he discarded cultures in liquids except for very special purposes. Since that time they have been looked upon with distrust, and results obtained with their aid suspected and questioned.

If there were some means of keeping liquids free from contamination, it is not unfair to say that they would be better adapted as a natural medium of bacterial life than any solid media ever suggested. This is self-evident for germs endowed with motility. One of the advantages of solid media is derived from the fact that any after-contaminations are quite easily detected with the unaided eye. This is not so readily done in the case of liquids. There are two ways of overcoming this difficulty: (1) by the use of a culture tube in which the parts are so adjusted that a momentary exposure for purposes of inoculation, etc., is practically without any danger whatever; (2) by frequently testing liquid cultures 
on solid media, preferably on gelatine. My experience with the culture tube devised by Dr. D. E. Salmon has been entirely satisfactory. Its efficiency may be considered quite perfect. As it has been fully described ${ }^{1}$ I need not dwell upon it here. The testing of liquid cultures is very simple and quickly accomplished. Either a minute portion is shaken up with liquified gelatine and the mixture poured on glass plates, or a platinum wire frequently dipped into the culture liquid is drawn several times across a layer of gelatine not yet congealed. In either case the developing colonies will determine the purity or impurity of the liquid culture. I have almost invariably found the thirteenth or fourteenth generation as pure as the first, and I should be surprised to find one out of every hundred impure.

I will grant unreservedly that test tubes plugged with cotton wool are not fit for liquid cultures. For gelatine in such tubes, when frequently exposed, is invariably invaded after a time by fungi or bacteria. The plug being a nidus for dust, its removal is always attended with danger. Because a culture tube which eliminates the use of a large removable plug is more costly, it does not follow that it should not be used in scientific research. We know that in the department of physics, chemistry and physiology, the most advanced work is of necessity performed with the most complex apparatus. That there are those who do not succeed in keeping liquid cultures pure, does not concern those who do. It behooves the former, in the interests of a true scientific spirit, to improve their apparatus and techinque instead of condemning the method.

Conceding then for the present that cultivations in liquids can be kept free from contamination, the point at issue is the employment of liquids for diagnostic purposes. Whoever has paid any attention to the multiplication of bacteria in nutritive fluids, has no doubt been surprised at the variety of features which present themselves, and at the regularity with which the same ones appear in cultures of the same microbe. To illustrate how many different characters may be used in determining the kind of bacteria and the purity of the cultivation, I will briefly outline a few of the more important ones as they have come under my own observation, referring the reader to $\mathrm{Miquel}^{2}$ for characters of bacteria obtained from the air, soil and water.

Every cultivation made in a tube shaped like a test-tube presents three regions for observation-the liquid itself, its surface,

1 First Annual Rep. Bureau of Animal Industry, Dept. Agriculture, 1834, p. 229; American Monthly Microscopical Journal, 1884, p. 185.

2 Annuaire de l' Observatoire de Montsouris pour l'an 1885, p. 577. 
and the bottom of the tube. In other words, there may be a membrane covering the liquid and a deposit in the bottom. With reference to the liquid itself, it may remain clear or become clouded. In the former case the growth may appear as a membrane or a deposit, or it may be disseminated through the fluid in minute granules, flakes or cloud-like masses. The cloudiness may be very faint-a slight opalescence-or it may be dense, approaching a turbidity. When shaken the cloudiness may be, as it were, set in motion, and thus show itself composed of elements, indistinguishably minute, or as granular or flocculent masses; or it may be impossible by shaking to disturb the uniform opalescence. The liquid may become colored. There may or may not be a membrane present. It may vary from a mere iridescent pellicle to a thick creamy layer. Its formation and growth should be carefully noted, together with its color, consistency and structure when fully formed. The deposit may be absent, very scanty, or quite abundant and colored. When agitated it will rise from the bottom in coarse or fine flakes, as a viscid ropy mass, or as a fine powder. In connection with these characters it is necessary to take into consideration the composition and reaction of the culture liquid. The temperature to which the culture is exposed has a marked effect upon the rapidity with which these characters appear. The odor and reaction of the culture of a certain age are also valuable in many cases.

When these various features, and many others not given above, are taken alone and in combination, we have for most cultures an almost positive means of diagnosis as well as a ready method of detecting contaminations, for these features are as a rule constant. In order to illustrate this statement I will write down a few features of the growth of Bacillus subtilis ${ }^{3}$ in a neutralized infusion of beef to which $1 \%$ peptone has been added. In a temperature of about $35^{\circ} \mathrm{C}$. the liquid becomes opalescent in from 6 to 8 hours. When agitated, rolling cloud-like masses are outlined by a condensation of the suspended bacteria. Within 24 hours an interlacing network, or islands of a whitish gelatinous deposit appear on the surface, which within another day are fused into a white papery membrane covering the entire surface. This membrane, which is not smooth, but puckered and pouched in a peculiar way, pushes its border up the sides of the tube, resembling at this stage the cup of an acorn. The liquid itself gradually clears up in the mean time until it is quite as limpid as before inoculation. This clearing up of the liquid, together with the pe-

${ }^{3}$ This bacillus can be obtained pure at any time by boiling in a water bath, for from $1 / 2$ to $3 / 4$ hour, a filtered infusion of hay contained in a flask plugged with cotton wool. 

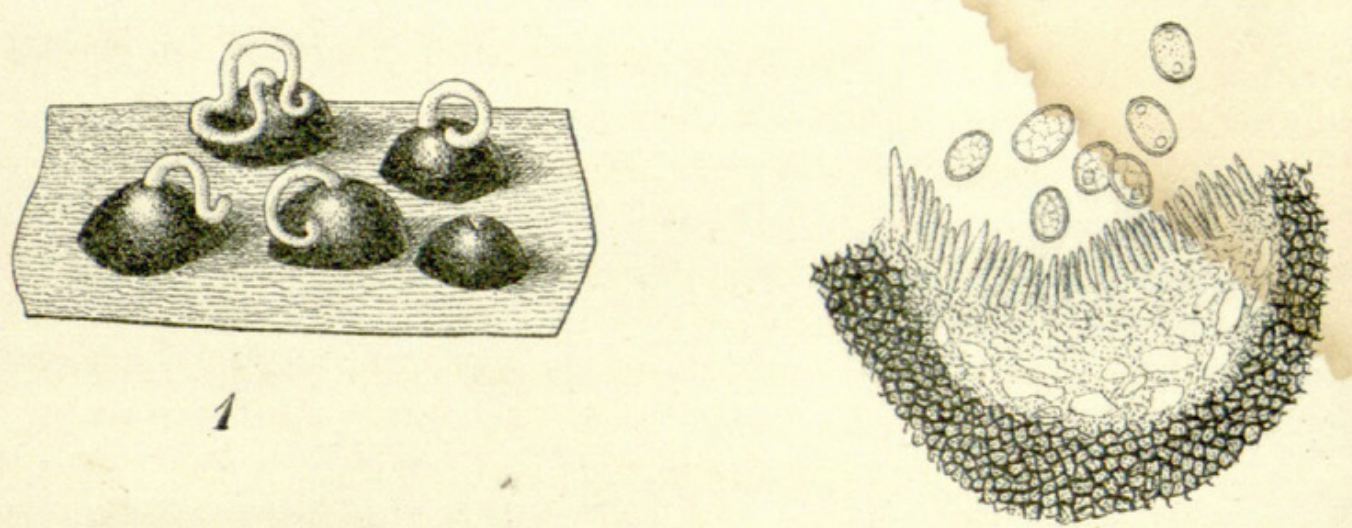

3

0

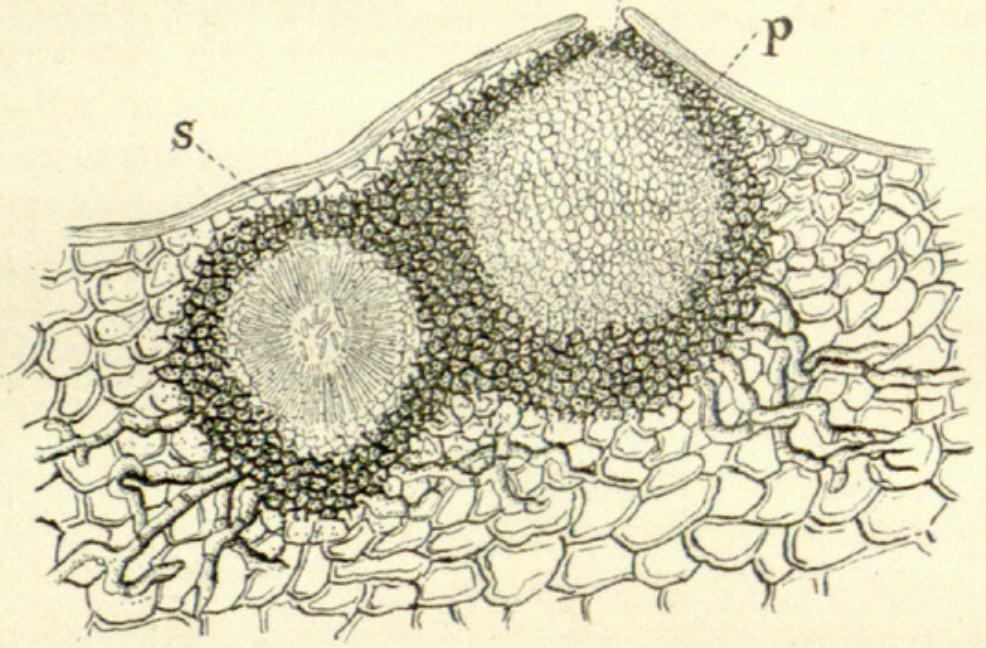

2

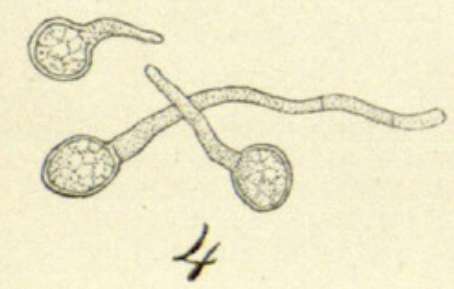

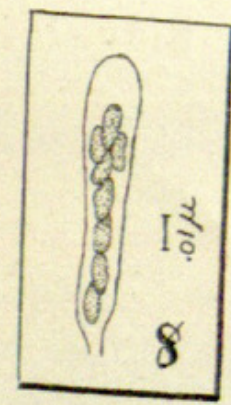

8

FL: 202 .

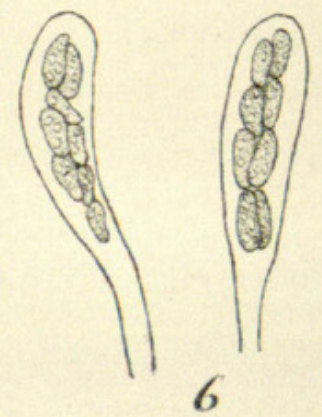

28

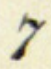




\section{$2 \mathrm{BHL}$ Biodiversity Heritage Library}

Smith, Theobald. 1886. "The Relative Value of Cultures in Liquid and Solid Media in the Diagnoses of Bacteria." Botanical gazette 11(11), 294-297. https://doi.org/10.1086/326031.

View This Item Online: $\underline{\text { https://www.biodiversitylibrary.org/item/87716 }}$

DOI: https://doi.org/10.1086/326031

Permalink: https://www.biodiversitylibrary.org/partpdf/221613

\section{Holding Institution}

Missouri Botanical Garden, Peter H. Raven Library

\section{Sponsored by}

Missouri Botanical Garden

\section{Copyright \& Reuse}

Copyright Status: Public domain. The BHL considers that this work is no longer under copyright protection.

This document was created from content at the Biodiversity Heritage Library, the world's largest open access digital library for biodiversity literature and archives. Visit BHL at https://www.biodiversitylibrary.org. 